\title{
Psychological Predictors of Facebook Use: A Literature Review
}

\author{
Yushi Jiang ${ }^{1}$ \\ "Mishal Hasnain Naqvi ${ }^{2}$ \\ "Muhammad Hasnain Abbas Naqvi ${ }^{1}$
}

ISchool of Bconomicis and Ilinnigement, Southwest Jiaotong Iniversity, (hengdu, (hinit

${ }^{2}$ School of Business, Sichutun Iniversity, (hengdul, (hinit

\begin{abstract}
Facebook has experienced remarkable development in recent years, and has become the most commonly used online social networking site (SNS). Due to its increasing importance and popularity among users, the platform has attracted attention from many academicians and researchers. The current paper discusses the key aspects and relevant empirical results of research carried out in relation to Facebook to date by applying a mapping technique as part of a systematic literature review. The method used in this study provides a detailed overview of the context to examine the magnitude and value of existing evidence on Facebook use. The findings offer interesting insights that researchers can use to diversify their investigations into SNS use concerning demographics and certain other antecedents. It also proposes a unique framework by which to understand the as yet unexplored dimensions of social networking sites.

Keywords: Social networking sites, literature review, motivations, personality traits, technology acceptance model, Facebook

JEL: M30, M39
\end{abstract}

In recent years, the extensive use of social media has opened new avenues for researchers to explore the role of social networking sites (SNSs) in terms of communication, human development, and realtime connection. SNS comprises a large network defined as web-based services that allow individuals to (i) construct a semi-public or public profile within a bounded system, (ii) clearly define a list of users with whom they interact, and (iii) view their list of connections and those made by others within the system (Boyd and Ellison, 2007; Marshall, Lefringhausen and Ferenczi, 2015). Facebook, the most popular and frequently used SNS, now has 2.37 billion monthly active users- Every day, at least 1.56 billion users log in to the site (Hutchinson, 2019).

The emergence of SNSs such as Facebook, Myspace, Renren, and WeChat has introduced a new means of communication and interaction in the e-commerce sector and influenced people's day-today interactions. However, Facebook in particular has received significant attention from both users and academicians, worldwide. Numerous previous studies have revealed the importance of SNSs in various fields including economics, information technology, medical, marketing, and psychology (Blachnio et al., 2016; Naqvi, Jiang and Naqvi, 2019; Naqvi et al., 2020).

Extant research on Facebook user behavior has considered a range of topics, such as motivation 
(Zhang et al., 2019), personality characteristics (Shchebetenko, 2019), privacy (Naqvi et al., 2019), and social capital formation (Phua, Jin and Kim, 2017). In this way, the existing literature has confirmed the importance of SNSs worldwide (Voorveld, 2019).

The primary purpose of the current article is to review this extant literature to enhance understanding of the phenomenon of social networking and to provide an overview of antecedents of Facebook use (see Figure 1). Our motivation is to categorically summarize recent results on the use of Facebook and to suggest future directions of study in relation to this SNS. In this review, we address two main aspects-individual factors pertinent to the use of Facebook and the effect of these factors on user behavior-and provide a framework based on extant analysis.

Another important reason for studying Facebook is to highlight the various activities performed on this platform (such as making connections, posting status updates, and sharing one's profile) so as to study human behavior by adopting new techniques. Since human behavior is really complex in nature, it is challenging to understand. With the development of such SNS it is becoming increasingly pertinent for researchers to study the behavior of real users of these sites through a realistic approach. There are currently millions of Facebook users (Naqvi et al., 2019), and the platform thus provides a unique opportunity to explore several key topics, such as how people connect with one another and how diverse user populations form their online identities.

The present study identifies motives for using Facebook e.g., narcissism, personality traits, privacy concerns, and self-esteem as having received significant theoretical consideration (Marwick and Boyd, 2014; Marshall et al., 2015; Skues, Williams and Wise, 2012; Zhang, Tang and Leung, 2011). These factors as a whole have a cumulative impact on user behavior; however, extant literature has not reviewed them together to examine Facebook use. Therefore, the current study fills this gap by conducting a comprehensive literature review on SNS usage behavior. The research is expected to be useful in identifying how distinctive characteristics of response can influence users' online participation. The selected variables describe the individual's intent to become an active member of a particular social networking site, and make it possible to explain and predict the ever-changing behavior of users concerning their participation in different web-based communities. In addition, we discuss the findings of confirmatory studies based on theoretical models such as the technology acceptance model (TAM). Previous studies have confirmed the substantial contribution of TAM in understanding the acceptance and adoption of new technology. Studies have also indicated that the parsimony and considerable predictive power of TAM is imperative for innovation acceptance (Naqvi et al., 2019). The literature has highlighted the significant development of TAM, which makes it possible to investigate the increasing popularity of SNSs and the way they are transforming user behavior. However, little is known about the mechanism through which SNS user behavior is explained by TAM. 


\section{Jiang et al.}

Therefore, it is essential to examine TAM more closely in order to obtain an understanding of its predictive power, particularly in SNS contexts. Based on the scenario mentioned above, this paper argues that TAM, narcissism, personality traits, self-esteem, privacy concerns, and other motives may impact SNS usage behavior.

In sum, the purpose of this study is to conduct a systematic review to explore evidence from recent literature regarding the factors and theoretical paradigm affecting SNS user behavior. It also provides valuable insights regarding the strengths and weaknesses of existing research, and makes some suggestions for future research. The study focuses on individuals' personal use of Facebook. The findings will help institutions and organizations to better understand how to utilize social networking sites in their day-to-day tasks.

Next two sections of this paper present an overview of Facebook and explain methodology. The literature on psychological predictors is then presented. The remainder of the paper consists of conclusion, limitations, and future research directions.

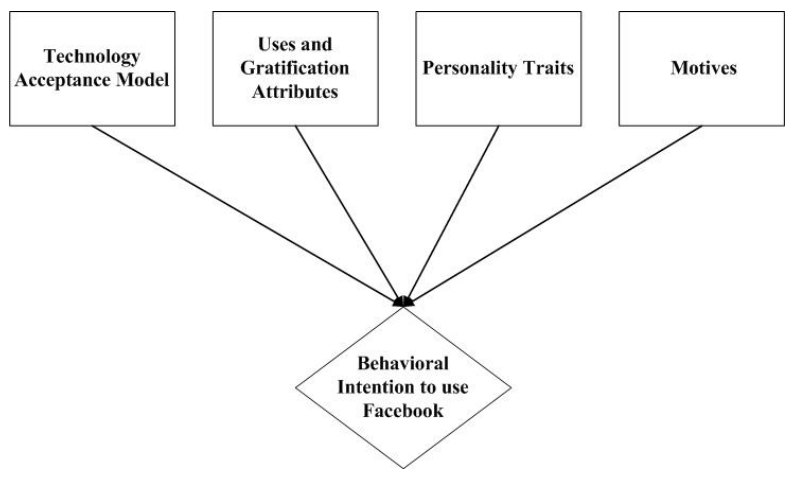

Source: Authors' Presentation

Figure 1. Factors Reviewed to Examine the SNS Use Intention

\section{Overview of Facebook}

Facebook is one of the most widely used SNS. It was launched in 2004, primarily for Harvard University students, and was opened to the public in 2006. Since its inception, the site has achieved immense recognition, and its popularity is increasing day-by-day (Yushi, Naqvi and Naqvi, 2018). The platform enables users to create profiles and build connections with people. The majority users of Facebook are university students (Ellison, Steinfield and Lampe, 2007; Lampe et al., 2011). Users use the platform not only to interact with each other but also to exchange information, share pictures, play games, comment on others' posts, and disclose personal information. In addition, the network offers a broad range of services, including promotional services for business, entertainment services, 
International Journal of Management, Economics and Social Sciences

relationship services, and marketing options for various products and services. Moreover, information about users' profiles can be used by businesses in their marketing campaigns. Political parties can also use Facebook to convey their plans and contact large pools of voters. Young users typically use Facebook for 60-120 minutes per day (Kalpidou et al., 2011). Privacy concerns have also been reported in past studies (Tan et al., 2012), with women found to be more privacy-conscious than men. Likewise, gender differences play an essential role, as women focus more on network building and change their profile pictures more often. In contrast, men have more friends and update their status more frequently as compared to women (Naqvi, Jiang and Naqvi, 2019; Naqvi et al., 2020; Yushi et al., 2018). In the present study, we present a framework that will act as a conceptual and theoretical foundation for utilizing social networking sites for multiple purposes. This approach will enable researchers to focus on the most pertinent variables and provide more precise insights on Facebook use. Thus, TAM is selected as the main model to explain the phenomenon under study.

\section{METHODOLOGY}

The present study used a mapping technique as part of a systematic review of the literature. This method provides a detailed overview of the context to examine the quality and quantity of existing evidence thereon. Moreover, it explores the gap in the present literature to determine requirements for new research in the subject area. The mapping approach followed is suggested by Kitchenham et al. (2009). Thus, research papers on SNS were identified by searching specific databases/search engine (explained in the next section). The studies were selected based on inclusion and exclusion criteria as outlined in Table 1. Following data extraction, relevant data were synthesized to examine the psychological predictors of SNS use. After detailing these processes and findings, interpretations, future research directions, and a conclusion are provided.

A holistic analysis is performed based on primary studies to address the purpose of the research. We targeted studies based on human participation and that have applied a range of methodological techniques, such as experiments, interviews, and surveys.

\section{-Article Search and Selection Strategy}

The following search strategy was used to find and select relevant articles for this study. First, combinations of search strings (see Table 2) were developed to find the most relevant research papers. Search strings that did not provide relevant articles were not considered further. The articles selection period for the study was 2010-2015, since in this period of time ample studies were published on user behavior on SNS in the context of psychological predictors. Three databases were used for data extraction: ACM Digital Library, Google Scholar, and Science Direct. These databases 


\section{Jiang et al.}

were targeted due to their reliability and authenticity, since the papers they contain have been peerreviewed, thus indicating the quality of the research. All publications in these databases consist of primary studies and literature reviews.

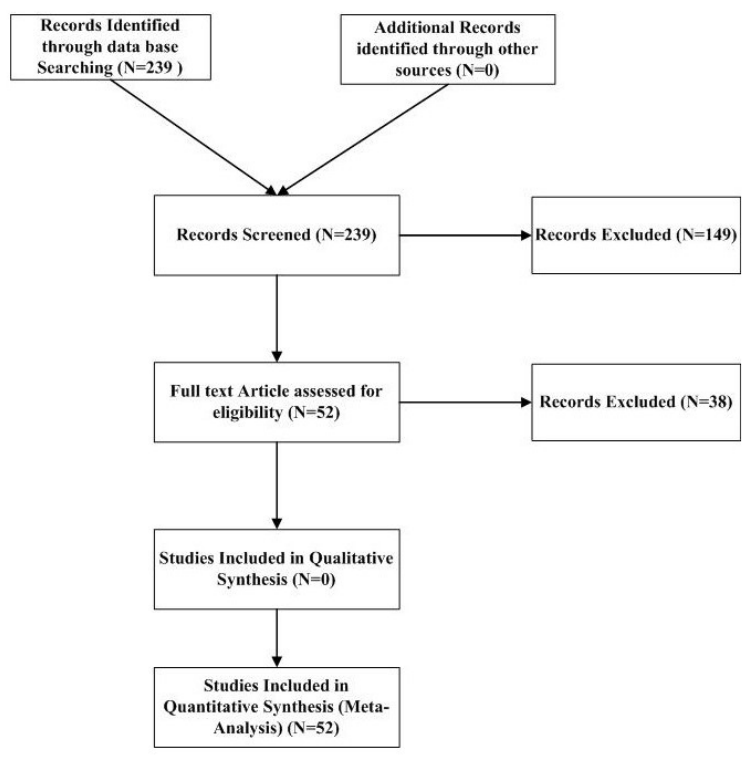

Source: Authors' Presentation

Figure 2. Prisma Flow Diagram

\begin{tabular}{|c|c|}
\hline \multirow{4}{*}{$\begin{array}{l}\text { Inclusion } \\
\text { Criteria }\end{array}$} & The abstract or title of the paper must have a search string \\
\hline & The paper must involve human participation and should be in English \\
\hline & The paper must focus on the user's behavior of SNS. \\
\hline & The methodology of the paper at least involved surveys, interviews, or experiment. \\
\hline \multirow{4}{*}{$\begin{array}{l}\text { Exclusion } \\
\text { Criteria }\end{array}$} & Extended abstracts conference proceedings and summaries, \\
\hline & Magazine features, short papers, and under review papers have excluded. \\
\hline & Papers published on topics such as politics, religion, healthcare, and drugs were \\
\hline & Excluded \\
\hline
\end{tabular}

Source: Authors' Presentation

Table 1. Inclusion and Exclusion Criteria

A total of 239 titles and abstracts of articles were examined to determine their relevance to the study; 149 articles were then excluded due to a lack of relevance. Of the remaining 90 articles, 52 were selected based on content assessment of their applicability.

Facebook and the Technology Acceptance Model 


\author{
Preliminary Strings Social networking sites, Facebook, social media use, SNS adoption, e- \\ commerce, online communication \\ Selected Strings $\quad$ Social networking sites, Facebook, SNS
}

Source: Authors' Presentation

\title{
Table 2. Search Strings
}

A range of methods has been employed to study Facebook. Some researchers have emphasized privacy and individual differences between users, while others have concentrated on exploratory analysis of a wide range of predictors pertinent to Facebook use. The most commonly used paradigm is Technology Acceptance Model (TAM), which measures the use of actual technology in the context of behavioral intention to use. Moreover, TAM has been combined with attitude and perceived usefulness, while perceived ease of use is considered by TAM as the central factor affecting behavioral plans to use via attitude formation (Davis et al., 1989). TAM has been so widely adopted by technology diffusion researchers because of its parsimony and lucidity. It is generally extended according to the nature of the study (Marangunić and Granić , 2015). Indeed, we identified 10 studies that have employed TAM in a modified form; these changes primarily comprise the incorporation of external variables (Legris et al., 2003). The factors included in TAM as external variables were adopted from the hedonic approach, including enjoyment (Ernst, Pfeiffer and Rothlauf, 2013), and playfulness (Hsu, Chang and Chen, 2012; Oum and Han, 2011). The results showed a significant effect of these variables on behavioral intention ( $\mathrm{Hu}$, Poston and Kettinger, 2011; Oum and Han, 2011), and an ancillary impact through attitude (Lee, Kim and Kim, 2011). Results found by Hsu et al. (2011) suggested that the influence of pleasure on the intention to use Facebook is significant; however, the authors also found a positive association between arousal and intention to use Facebook, revealing that people enjoy their time interacting via Facebook. These results are in line with Rauniar et al. (2014), and Wise et al. (2010), who measured the emotional responses of Facebook users. Their research revealed that searching for peers on Facebook, or using a friend profile, is more entertaining as compared to finding connections through news feeds, depending on the psychological measure of emotional activation. These findings are similar to those by Mauri et al. (2011), and Rauch et al. (2014), who showed that a state of arousal and valence occurs when using Facebook. Psychological factors associated with SNS use, such as telepresence (Kwon and Wen, 2010; Lin and Lu, 2011) There, sense of belonging (Strayhorn, 2012), privacy (Wilson, 2012) and flow (Kwak et al., 2014). Sombutpibool (2011) provided a new way of perceiving and accepting these technologies. These 


\section{Jiang et al.}

factors affect user behavior with regard to the adoption of SNS varies from time to time. Among psychological variables affecting the use of technology, loneliness has been found to be an essential predictor of Facebook use (Lee, Noh and Koo, 2013). Lastly, several social factors have been added to TAM to measure intention to use. For example, social identity (Cheung, Chiu and Lee, 2011; Hu et al., 2011; Zhou, 2011), trust (Oum and Han, 2011), and social norms (Cheung et al., 2011; Hu et al., 2011; Leng et al., 2011) have positive impact for intention to use. Although altruism has also been delineated as an important variable influencing actual usage of Facebook, increasing perceived encouragement and perceived ease of use (Flynn and Black, 2011; Ma and Chan, 2014), it was eliminated from Oum and Han's (2011) framework since results obtained in this regard were not significant.

It is notable that social factors (such as social norms and social identity) have been found useful in forming a positive attitude regarding the use of Facebook, which ultimately enhances actual use of the technology. Many studies have reported the significant influence of satisfaction on the use of Facebook. For instance, Cheung et al. (2011) investigated the "we intention paradigm", Ma and Chan (2014) considered social motivation, Zhang et al. (2011) explored collective self-esteem, and Marwick and Boyd (2014) investigated belonging; all these studies confirmed the advantages of using TAM in studies on the use of Facebook.

TAM has also been verified as a constructive model for comprehending and describing technology usage behavior. It has been applied in several empirical studies; the techniques employed alongside the model are high quality and have produced quantitatively reliable outcomes. Studies have revealed that the effect of various factors on intention to use technology fluctuates to different levels during the technology implementation phase (Naqvi et al., 2019).

Conversely, a closer analysis of TAM indicates some weaknesses that need to be addressed. For example, most of the research related to TAM has used student samples (Lampe et al., 2011), which gives rise to concerns regarding generalizability. There is thus a need to change the sample population to obtain more authentic results and maintain the integrity of the model. Most TAM-related studies have not investigated the social networking system used; instead, they have focused on measuring self-reported use, which is not an appropriate exploration. The predictive capacity of TAM can be challenged if it is not integrated with a comprehensive model, such as via the addition of external factors, and direct, indirect, mediating, and moderating effects on the adoption and use of technology. Apart from adding usage-related constructs to the TAM (Marangunić and Granić , 2015), there is a need to focus on specific social and organizational factors that could increase its effectiveness.

Facebook and Personality Traits 
International Journal of Management, Economics and Social Sciences

Numerous studies have measured the correlation between Facebook use and personality characteristics. For example, studies have reported on the significant use of the Big Five personality model (Lee, Ahn, and Kim, 2014; Marshall et al., 2015). The model comprises of five dimensions of personality: extraversion, neuroticism, openness to experience, agreeableness, and conscientiousness (Costa and McCrae, 1992). Extraversion is related to being assertive, seeking social connections, and loquacity; neuroticism is associated with anxiety, mood swings, and emotional imbalance, such that people with a higher level of neuroticism prefer to be alone rather than being connected socially; openness to experience includes welcoming new options, such as exploring and learning about new prospects; agreeableness is a state of being cooperative, collaborative, warm, and synergic; and conscientiousness is related to diligence and caution (Marshall et al., 2015). According to several authors (Correa et al., 2010; Lee et al., 2014; Marshall et al., 2015; Moore and McElroy, 2012), these personality factors differentiate users of SNSs from one another. The research further confirmed that openness to experience and extraversion are meaningfully linked with SNSs use, while emotional stability is inversely associated therewith.

Variations regarding age and gender have also been proven. It is noteworthy that extrovert males and females frequently use SNSs, but males with emotional imbalances are the most frequent users (Sampasa-Kanyinga and Lewis, 2015). Openness to experience is a crucial variable that predicts social media use, but only for older users (Leist, 2013). Intention to use Facebook is distinguished by personality characteristics; for example, studies (e.g., Amichai-Hamburger and Vinitzky, 2010; Gosling et al., 2011) have reported that extroverts are the most regular users of Facebook, especially from the viewpoint of communication. Extroverts also use different SNSs for day-to-day correspondence versus networking. Users with higher neuroticism and agreeableness achieve a sense of belonging by using SNSs, while conscientiousness is concerned with the fulfillment of self-presentational needs. Eftekhar, Fullwood and Morris (2014) showed that extroverts are outgoing and make more connections via Facebook as compared to those who are more introverted, while people with highin neuroticism make more frequent use of their Facebook wall. Hence, the study concluded that personality traits influence Facebook use.

Karl, Peluchette and Schlaegel (2010) examined how cultural variations affect the information users posts on Facebook. It was found that German students upload less ambiguous content as compared to US students. According to Lee et al. (2012), personality factors, such as agreeableness and conscientiousness, impact the chances of the individual posting vague content. Kim, Kim and Nam (2010), and Chang (2015) documented that Facebook use can be predicted with reference to the individual's self-construal-that is, association with their surroundings-and social interdependence.

Moreover, interdependent self-construal is concerned with the collectivist aspect of culture. Wilson, 


\section{Jiang et al.}

Fornasier and White (2010) found that self-esteem and personality traits are core predictors of SNSs use, and also determinants of addictive tendencies, such that users with low self-esteem use Facebook to build social capital, since Facebook provides a barrier-free platform for communication and connection to a large group of people. Many other studies (e.g., Carpenter, 2012; Davenport et al., 2014; Marshall et al., 2015; Skues et al., 2012) investigated the link between narcissism and Facebook usage. Narcissism has been defined as "a pattern of traits and behaviors which signify infatuation and obsession with one's self to the exclusion of all others and the egoistic and ruthless pursuit of one's gratification, dominance, and ambition" (Bushman and Baumester, 1998). As per Mehdizadeh (2010), narcissism has a significant positive relationship with intention to use Facebook, and also influences self-promotion via features such as status updates and profile pictures. Bergman et al. (2011) found no difference in the time users with various levels of narcissism spend on Facebook. The variation was found to be based on the motives for using Facebook; however, users who were at the second level of narcissism were found to be more conscious about making friends, showed more desire to post their current status, and more likely to display a positive profile image. Accordingly, Carpenter (2012) found that trends regarding Facebook use entail two types of narcissism: exhibitionism and grandiose, which refers to getting attention, exploitativeness and entitlement, that is associated with a state of worthiness and denying the feelings of others. The research reported that these traits are similar to antisocial behavior. Narcissist users use Facebook as a leisure activity and consider it as a hobby, adopting it for the sake of romanticism and pretentious purposes. Similarly, they more regularly update their Facebook profiles and put up more attractive pictures.

Some studies have made suggestions for the core of Facebook to be changed with the view of developing a broader understanding of the factors affecting the use of Facebook. According to such authors, the Big Five model may not be sufficient to understand the reasons people use Facebook (Fox and Rooney, 2015; Sun and Wu, 2012).

Based on the above discussion, our understanding of Facebook users' personalities is incomplete. Since SNSs vary in their content, target audiences, and use (Shi et al., 2018), it is unclear whether extensive research on SNSs other than Facebook can be applied to Facebook. Thus, more in-depth analysis seems to be required regarding the personality traits of Facebook users. In addition, future investigations may consider other demographic factors in this domain. Despite the abundance of literature on the topic, more studies are needed on personal characteristics and their effect on Facebook use (Kim and Chock, 2017; Marshall et al., 2015). Currently, most of the literature is based on a wide range of SNSs, homogeneous samples, or samples derived solely from the US, which makes generalization difficult (Miller and Melton, 2015). Moreover, future research could explore chan- 
International Journal of Management, Economics and Social Sciences

ges that have occurred due to the rapid advancement of SNS technology, changes in Facebook features, and evolutions in the user experience. Such studies would be particularly relevant from the viewpoint of personality traits, since the decisions of early adopters may differ from those of newer users. Table 3 (see Appendix-I) summarizes the sources used in our literature review.

\section{Motives for using Facebook}

Existing research on Facebook has focused on how users present themselves and how they communicate with peers on Facebook. However, although a large number of diverse findings have already been reported, there are still opportunities for improvement and exploration of aspects that have not yet been considered.

The main motive for using an SNS is to build new connections or maintain existing ones. Users adopt SNSs to introduce themselves to others, and share information and interests, which ultimately impacts their social capital (Ellison et al., 2007; Ellison et al., 2014). In addition, Ellison et al. (2007) reported that people with low self-esteem and satisfaction gain more benefits from Facebook. Jin (2013) considered the social enhancement proposition, wherein the "rich get richer", and the social compensation proposition, wherein the "poor get richer", in the context of Facebook. The results showed that extroverts are more positively influenced by the use of Facebook, whereas less popular people benefit from the social compensation proposition. The study further emphasized that Facebook is a favorable mechanism for finding new people. Several studies have also explored motives for using Facebook (Al-Debei, Al-Lozi and Papazafeiropoulou, 2013; Hunt, Atkin and Krishnan, 2012; Suki, Ramaya and Ly, 2012) such as socializing, content sharing, time utilization, making new friends, dating, family networking, and surfing profiles. The uses and the gratification paradigm describe motivations pertaining to personal identity, information, social interaction, and entertainment as drivers of Facebook use (Whiting and Williams, 2013). In addition, Nadkarni and Hofmann (2012) found two main social reasons for using Facebook: impression management, and desire for social acceptance and attachment to others. These needs, however, rely on other variables; for instance, personality, demographic, and cultural variables. The majority of studies have found that motives for using Facebook are based on the needs and personalities of users, where socially ambitious and shy users spend more time on Facebook as compared to those with high self-esteem (Wilcox, 2012). Nevertheless, personality has not been found to be a direct motivator to use Facebook (Hughes, 2012); thus, there are other motives for using Facebook, such as making new friends online. It is not necessary that these online friends are also offline friends; however, having a large number of friends online can decrease the frequency of meeting and getting to know each other in offline settings. Furthermore, many users accept requests from old school friends they once interacted with but have 


\section{Jiang et al.}

not had contact with for a long period.

Various other studies have also indicated that making contact with friends is not a prime driver for using Facebook (Fox and Warber, 2013). According to Chang et al. (2015), keeping in touch with people is a primary reason for using Facebook; however, people prefer to interact with new users and enjoy viewing their profiles. Correspondingly, Al-Debei et al. (2013) suggested that the desire for communication with others is the main objective for making an account on Facebook, rather than entertainment value and social support. Respondents in Hew's (2011) study reported that the reason behind their frequent use of Facebook was self-promotion within a larger web of communication.

Similarly, people who are high in narcissism and low in self-esteem have a strong tendency to spend time on Facebook (Mehdizadeh, 2010). Another way of expressing oneself is to upload photos on Facebook, which helps to control one's self-image (Kwak et al., 2014). Statistics show that young individuals use Facebook for study purposes, such as sharing notes and projects (Junco, 2015; Kabilan, Ahmad and Abidin, 2010; Lampe et al., 2011). Other research has found that a primary motive for using Facebook is to pass time and reduce boredom (Hew, 2011). Indeed, several researchers (e.g., Krishnan and Atkin, 2014; Lee and Chan, 2015; Sponcil and Gitimu, 2013; Whiting and Williams, 2013) have found that bored users spend the most time on Facebook and fear communication in offline settings. Another reason for using Facebook is to convey one's intent, such as election participation. However, Facebook can also be used for task management, such as to make a record of friends' birthdays, and to store email addresses and phone numbers. Some users have a profile on Facebook because it gives them a superior feeling (Hew, 2011). The different reasons for using Facebook have strong correlations with privacy settings and usage trends. Users may be able to make more friends with moderate privacy settings (e.g., more extensive profile access). People who belong to such a group are pleasure-oriented, and self-presentation is another main purpose for using Facebook (Fox and Warber, 2014; Lee et al., 2014).

Some cultural variations in use have also been noted by Kim et al. (2011). They compared South Korea and the US, finding a significant effect of cultural differences on motivation to use SNSs. Likewise, Brandtzæg, Lüders and Skjetne (2010), and Strayhorn (2012) identified similarities and differences regarding SNSs use between adults and younger groups of users, which further revealed that adults' motivation to use Facebook is to connect with old friends. In contrast, young users prefer to contact people they meet daily, and use Facebook for sharing pictures; friends' connection, but adults viewed it as a nostalgic character.

Based on the above discussion, there are clearly various motives to use SNSs. Individuals tend to stick to a single SNS to fulfill their needs. A major limitation of extant studies is that they all explored similar motives for using SNSs. Thus, there is a need to conduct further empirical investigations regar- 
International Journal of Management, Economics and Social Sciences

ding motives for using SNSs, and to draw comparisons with the available literature. This could provide a novel contribution to the field, as the intention to use SNSs varies in terms of demographics. Moreover, the acceptance rate of SNSs may have increased since 2015. It would be interesting to measure motives for using SNSs across different countries, as the motives of Asian users, for instance, may differ from those of European or American users.

\section{IMPLICATIONS}

The current study focused on the use of social networking sites particularly Facebook, and draws the attention towards some significant implications. There is a need to systematically develop a method for targeting population other than students to measure the usage behavior. Moreover, exploratory technique can offer prospects for the recognition of distinctive indicators which may increase the practical and theoretical validity. The proposed framework of social networking sites will provide a new direction in existing literature to investigate user intention to use these sites in a new perspective.

The review conducted in this paper covers a range of topics in psychology that explain individuals' use of Facebook. Facebook offers a wide range of applications and has become an essential instrument in several areas of individual activity. It is difficult to foresee whether Facebook will replace other forms of communication tools; however, it has become one of the most popular means of virtual communication and dispersing information.

Concurrently, the review highlighted several issues that require further exploration. For example, more attention needs to be paid to understanding the unique role of SNSs (particularly Facebook) by integrating items and variables into a new direction, and implementing these designs in different countries. Moreover, the results regarding motivational factors, personality characteristics, and other individual traits that explain Facebook use are multipurpose. Finally, the role of hedonic, social, and personal variables confirms the importance of TAM. Based on the investigated papers, most of the available literature has focused on the use and adoption of technology. This limited empirical evidence calls for new avenues of exploration in the context of SNSs. Thus, we suggest research frameworks, as outlined in Figure 3 and Figure 4, providing directions to measure the underexplored dimensions of SNSs.

\section{LIMITATIONS AND FUTURE DIRECTIONS}

The present study is subject to several limitations. First, its emphasis on only one SNS, Facebook, for analysis has both benefits and drawbacks. We used a narrow approach that nevertheless provides several meaningful insights about trends in Facebook use. Therefore, the scope and generalizability of 


\section{Jiang et al.}

the study are also limited. Second, we only covered casual Facebook use, and did not consider more formal settings/environments. Third, we analyzed this phenomenon at an individual level, considering only those determinants that affect Facebook use, and paid little attention to the technical aspects of using this SNS. Fourth, in order to obtain standardized results, the selection strategy is beneficial for a

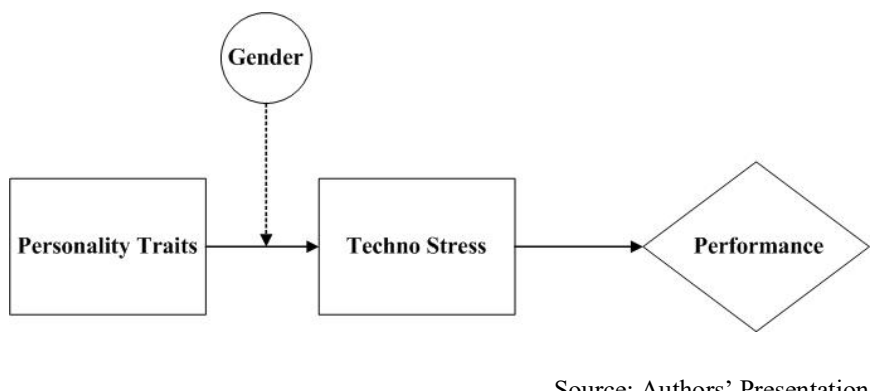

Figure 3. Proposed Research Framework No.1

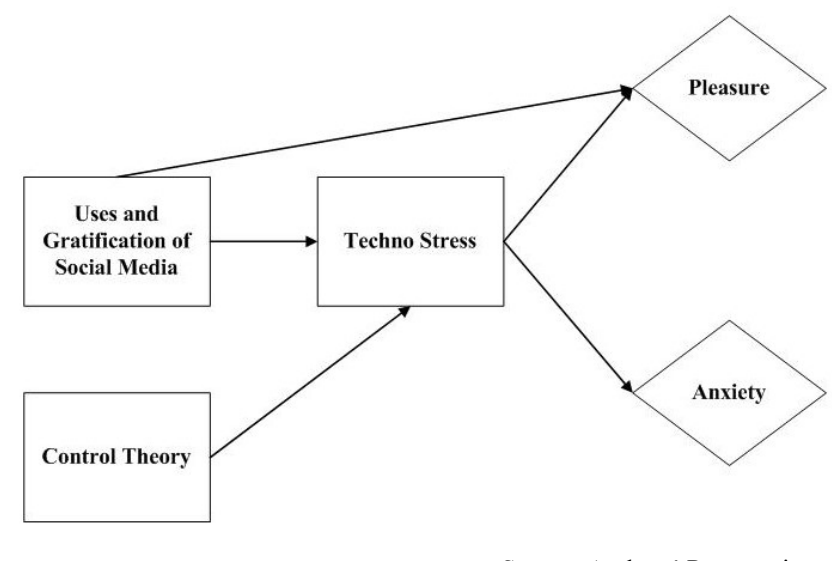

Figure 4. Proposed Research Framework No.2

study that is different from other Facebook reviews, which were explained in a broader sense. Finally, we chose peer-reviewed journals from only one field of study i.e., psychology-and for only 20102015, which represents another major limitation. Future research could consider more recent studies to derive a clearer understanding of the phenomenon. Future research could also investigate motives to use Facebook by applying the unified theory of personality in addition to the Big Five model. Behavioral intention to use SNSs can also be measured through various theoretical paradigms, such as control theory. In addition, future research should explore how adverts on SNSs capture the attention of users. Research can also be conducted on privacy to measure how this predictor varies between 
International Journal of Management, Economics and Social Sciences

different nationalities, and to what extent privacy settings parallel actual settings, since the existing literature has identified a secure link between personality and Facebook use. Most extant studies have been found to use student samples. Thus, future research should explore the robustness of these findings using larger samples from more global and diversified populations. Moreover, many studies in this context are quite recent, and the time frame is of less concern. It is therefore suggested that new research on friendship behavior be compared with extant articles, since the advantages and disadvantages of sharing information may influence friendship behavior.

\section{REFERENCES}

Al-Debei, M. M., Al-Lozi, E. \& Papazafeiropoulou, A. (2013). Why people keep coming back to Facebook: Explaining and predicting continuance participation from an extended theory of planned behaviour perspective. Decision Support Systems, 55(1): 43-54. https://doi.org/10.1016/j.dss.2012.12.032

Amichai-Hamburger, Y. \& Vinitzky, G. (2010). Social network use and personality. Computers in Human Behavior, 26(6): 12891295.

Bł achnio, A., Przepiorka, A., Bał akier, E. \& Boruch, W. (2016). Who discloses the most on Facebook? Computers in Human Behavior, 55, 664-667. https://doi.org/10.1016/j.chb.2010.03.018

Bergman, S. M., Fearrington, M. E., Davenport, S. W. \& Bergman, J. Z. (2011). Millennials, narcissism, and social networking: What narcissists do on social networking sites and why. Personality and Individual Differences, 50(5): 706-711. https://doi.org/10.1016/j.paid.2010.12.022

Brandtzæg, P. B., Lüders, M. \& Skjetne, J. H. (2010). Too many Facebook "friends"? Content sharing and sociability versus the need for privacy in social network sites. International Journal of Human-Computer Interaction, 26(11-12): 1006-1030. https://doi.org/10.1080/10447318.2010.516719

Bushman, B. J. \& Baumeister, R. F. (1998). Threatened egotism, narcissism, self-esteem, and direct and displaced aggression: Does self-love or self-hate lead to violence? Journal of Personality and Social Psychology, 75(1): 219-229. https://doi.org/10.1037/0022-3514.75.1.219

Boyd, D. M., \& Ellison, N. B. (2007). Social network sites: Definition, history, and scholarship. Journal of Computer-Mediated Communication, 13(1): 210-230. https://doi.org/10.1111/j.1083-6101.2007.00393.x

Carpenter, C. J. (2012). Narcissism on Facebook: Self-promotional and anti-social behavior. Personality and Individual Differences, 52(4): 482-486. https://doi.org/10.1016/j.paid.2011.11.011

Chang, C. (2015). Self-construal and Facebook activities: Exploring differences in social interaction orientation. Computers in Human Behavior, 53, 91-101. https://doi.org/10.1016/j.chb.2015.06.049

Chang, C. C., Hung, S. W., Cheng, M. J. \& Wu, C. Y. (2015). Exploring the intention to continue using social networking sites: The case of Facebook. Technological Forecasting and Social Change, 95, 48-56. https://doi.org/10.1016/j.techfore.2014.03.012

Cheung, C. M., Chiu, P. Y. \& Lee, M. K. (2011). Online social networks: Why do students use Facebook? Computers in Human Behavior, 27(4): 1337-1343. https://doi.org/10.1016/j.chb.2010.07.028

Correa, T., Hinsley, A. W. \& De Zuniga, H. G. (2010). Who interacts on the web? The intersection of users' personality and social media use. Computers in Human Behavior, 26(2): 247-253. https://doi.org/10.1016/j.chb.2009.09.003

Costa Jr, P. T. \& McCrae, R. R. (1992). Four ways five factors are basic. Personality and Individual Differences, 13(6): 653665. https://doi.org/10.1016/0191-8869(92)90236-I

Davenport, S. W., Bergman, S. M., Bergman, J. Z. \& Fearrington, M. E. (2014). Twitter versus Facebook: Exploring the role of narcissism in the motives and usage of different social media platforms. Computers in Human Behavior, 32, $212-220$. https://doi.org/10.1016/j.chb.2013.12.011

Davis, F. D., Bagozzi, R. P. \& Warshaw, P. R. (1989). User acceptance of computer technology: a comparison of two theoretical models. Management Science, 35(8): 982-1003. https://doi.org/10.1287/mnsc.35.8.982

Eftekhar, A., Fullwood, C. \& Morris, N. (2014). Capturing personality from Facebook photos and photo-related activities: How much exposure do you need? Computers in Human Behavior, 37, 162-170. https://doi.org/10.1016/j.chb.2014.04.048

Ellison, N. B., Steinfield, C. \& Lampe, C. (2007). The benefits of Facebook "friends": Social capital and college students' use of online social network sites. Journal of Computer-Mediated Communication, 12(4): 1143-1168. https://doi.org/10.1111/j.1083-6101.2007.00367.x

Ellison, N. B., Vitak, J., Gray, R. \& Lampe, C. (2014). Cultivating social resources on social network sites: Facebook relationship maintenance behaviors and their role in social capital processes. Journal of Computer-Mediated Communication, 19(4): 855-870. https://doi.org/10.1111/jcc4.12078

Ernst, C. P. H., Pfeiffer, J., \& Rothlauf, F. (2013). Hedonic and utilitarian motivations of social network site adoption. Johannes Gutenberg University Mainz: Working Papers in Information Systems and Business Administration, 1-14. 


\section{Jiang et al.}

Flynn, S. V. \& Black, L. L. (2011). An emergent theory of altruism and self-interest. Journal of Counseling and Development, 89(4): 459-469. https://doi.org/10.1002/j.1556-6676.2011.tb02843.x

Fox, J. \& Rooney, M. C. (2015). The dark triad and trait self-objectification as predictors of men's use and self-presentation behaviors on social networking sites. Personality and Individual Differences, 76, $161-165$. https://doi.org/10.1016/j.paid.2014.12.017

Fox, J. \& Warber, K. M. (2013). Romantic relationship development in the age of Facebook: An exploratory study of emerging adults' perceptions, motives, and behaviors. Cyberpsychology, Behavior and Social Networking, 16(1): 3-7. https://doi.org/10.1089/cyber.2012.0288

Gosling, S. D., Augustine, A. A., Vazire, S., Holtzman, N. \& Gaddis, S. (2011). Manifestations of personality in online social networks: Self-reported Facebook-related behaviors and observable profile information. Cyberpsychology, Behavior and Social Networking, 14(9): 483-488. https://doi.org/10.1089/cyber.2010.0087

Hew, K. F. (2011). Students' and teachers' use of Facebook. Computers in Human Behavior, 27(2): 662-676. https://doi.org/10.1016/j.chb.2010.11.020

Hsu, C. L., Chang, K. C. \& Chen, M. C. (2012). The impact of website quality on customer satisfaction and purchase intention: perceived playfulness and perceived flow as mediators. Information Systems and e-Business Management, 10(4): 549-570. https://doi.org/10.1007/s10257-011-0181-5

Hughes, D. J., Rowe, M., Batey, M. \& Lee, A. (2012). A tale of two sites: Twitter vs. Facebook and the personality predictors of social media usage. Computers in Human Behavior, 28(2): 561-569. https://doi.org/10.1016/j.chb.2011.11.001

Hunt, D., Atkin, D. \& Krishnan, A. (2012). The influence of computer-mediated communication apprehension on motives for Facebook use. Journal of Broadcasting and Electronic Media, 56(2): 187-202. https://doi.org/10.1080/08838151.2012.678717

Hutchinson, A. (2019). Facebook reaches 2.38 billion users, beats revenue estimates in latest update. Social Media Today. Retrieved from https://www.socialmediatoday.com/news/facebook-reaches-238- billion-users-beats-revenue-estimatesin-latest-upda/553403/.

Jin, C. (2013). The perspective of a revised TRAM on social capital building: The case of Facebook usage. Information and Management, 50(4): 162-168. https://doi.org/10.1016/j.im.2013.03.002

Junco, R. (2015). Student class standing, Facebook use, and academic performance. Journal of Applied Developmental Psychology, 36, 18-29. https://doi.org/10.1016/j.appdev.2014.11.001

Kabilan, M. K., Ahmad, N. \& Abidin, M. J. Z. (2010). Facebook: An online environment for learning of English in institutions of higher education? The Internet and Higher Education, 13(4): 179-187. https://doi.org/10.1016/j.iheduc.2010.07.003

Kalpidou, M., Costin, D. \& Morris, J. (2011). The relationship between Facebook and the well-being of undergraduate college students. Cyberpsychology, Behavior, and Social Networking, 14(4): 183-189. https://doi.org/10.1089/cyber.2010.0061

Karl, K., Peluchette, J. \& Schlaegel, C. (2010). Who's posting Facebook faux pas? A cross-cultural examination of personality differences. International Journal of Selection and Assessment, 18(2): 174-186. https://doi.org/10.1111/j.14682389.2010.00499.x

Kim, J. H., Kim, M. S. \& Nam, Y. (2010). An analysis of self-construals, motivations, Facebook use, and user satisfaction. International Journal of Human-Computer Interaction, 26(11- 12): 1077-1099. https://doi.org/10.1080/10447318.2010.516726

Kim, J. W. \& Chock, T. M. (2017). Personality traits and psychological motivations predicting selfie posting behaviors on social networking sites. Telematics and Informatics, 34(5): 560-571. https://doi.org/10.1016/j.tele.2016.11.006

Kim, Y., Sohn, D. \& Choi, S. M. (2011). Cultural difference in motivations for using social network sites: A comparative study of American and Korean college students. Computers in Human Behavior, 27(1): 365-372. https://doi.org/10.1016/j.chb.2010.08.015

Kitchenham, B. A., Brereton, O. P., Budgen, D., Turner, M., Bailey, J. \& Linkman, S. (2009). Systematic literature reviews in software engineering: A systematic literature review. Information and Software Technology, 51(1): 7-15. https://doi.org/10.1016/j.infsof.2008.09.009

Krishnan, A. \& Atkin, D. (2014). Individual differences in social networking site users: The interplay between antecedents and consequential effect on level of activity. Computers in Human Behavior, 40, 111-118. https://doi.org/10.1016/j.chb.2014.07.045

Kwak, K. T., Choi, S. K. \& Lee, B. G. (2014). SNS flow, SNS self-disclosure and post hoc interpersonal relations change: Focused on Korean Facebook user. Computers in Human Behavior, 31, 294-304. https://doi.org/10.1016/j.chb.2013.10.046

Kwon, O. \& Wen, Y. (2010). An empirical study of the factors affecting social network service use. Computers in Human Behavior, 26(2): 254-263. https://doi.org/10.1016/j.chb.2009.04.011

Lampe, C., Wohn, D. Y., Vitak, J., Ellison, N. B. \& Wash, R. (2011). Student use of Facebook for organizing collaborative classroom activities. International Journal of Computer-Supported Collaborative Learning, 6(3): 329-347. https://doi.org/10.1007/s11412-011-9115-y

Lee, E., Ahn, J. \& Kim, Y. J. (2014). Personality traits and self-presentation at Facebook. Personality and Individual Differences, 69, 162-167. https://doi.org/10.1016/j.paid.2014.05.020

Lee, F. L. \& Chan, J. M. (2015). Digital media use and participation leadership in social protests: The case of Tiananmen commemoration in Hong Kong. Telematics and Informatics, 32(4): 879-889. https://doi.org/10.1016/j.tele.2015.04.013

Lee, K. T., Noh, M. J. \& Koo, D. M. (2013). Lonely people are no longer lonely on social networking sites: The mediating role of self-disclosure and social support. Cyberpsychology, Behavior and Social Networking, 16(6): 413-418. https://doi.org/10.1089/cyber.2012.0553 
International Journal of Management, Economics and Social Sciences

Leng, G. S., Lada, S., Muhammad, M. Z., Ibrahim, A. A. H. A. \& Amboala, T. (1970). An exploration of social networking sites (SNS) adoption in Malaysia using technology acceptance model (TAM): Theory of planned behavior (TPB) and intrinsic motivation. The Journal of Internet Banking and Commerce, 16(2): 1-27.

Legris, P., Ingham, J., \& Collerette, P. (2003). Why do people use information technology? A critical review of the technology acceptance model. Information and Management, 40(3): 191-204. https://doi.org/10.1016/S0378-7206(01)00143-4

Leist, A. K. (2013). Social media use of older adults: A mini-review. Gerontology, 59(4): 378-384. https://doi.org/10.1159/000346818

Lin, K. Y. \& Lu, H. P. (2011). Intention to continue using Facebook fan pages from the perspective of social capital theory. Cyberpsychology, Behavior and Social Networking, 14(10): 565-570. https://doi.org/10.1089/cyber.2010.0472

Ma, W. W. \& Chan, A. (2014). Knowledge sharing and social media: Altruism, perceived online attachment motivation, and perceived online relationship commitment. Computers in Human Behavior, 39, 51-58. https://doi.org/10.1016/j.chb.2014.06.015

Marangunić , N. \& Granić , A. (2015). Technology acceptance model: A literature review from 1986 to 2013. Universal Access in the Information Society, 14(1): 81-95. https://doi.org/10.1007/s10209-014-0348-1

Marshall, T. C., Lefringhausen, K. \& Ferenczi, N. (2015). The Big Five, self-esteem, and narcissism as predictors of the topics people write about in Facebook status updates. Personality and Individual Differences, 85, 35-40. https://doi.org/10.1016/j.paid.2015.04.039

Marwick, A. E. \& Boyd, D. (2014). Networked privacy: How teenagers negotiate context in social media. New Media and Society, 16(7): 1051-1067. https://doi.org/10.1177/1461444814543995

Mauri, M., Cipresso, P., Balgera, A., Villamira, M. \& Riva, G. (2011). Why is Facebook so successful? Psychophysiological measures describe a core flow state while using Facebook. Cyberpsychology, Behavior and Social Networking, 14(12): 723731. https://doi.org/10.1089/cyber.2010.0377

Mehdizadeh, S. (2010). Self-presentation 2.0: Narcissism and self-esteem on Facebook. Cyberpsychology, Behavior and Social Networking, 13(4): 357-364. https://doi.org/10.1089/cyber.2009.0257

Miller, R. \& Melton, J. (2015). College students and risk-taking behaviour on Twitter versus Facebook. Behaviour and Information Technology, 34(7): 678-684. https://doi.org/10.1080/0144929X.2014.1003325

Moore, K. \& McElroy, J. C. (2012). The influence of personality on Facebook usage, wall postings, and regret. Computers in Human Behavior, 28(1): 267-274. https://doi.org/10.1016/j.chb.2011.09.009

Nadkarni, A. \& Hofmann, S. G. (2012). Why do people use Facebook? Personality and Individual Differences, 52(3): $243-249$. https://doi.org/10.1016/j.paid.2011.11.007

Naqvi, M., Li, S., Jiang, Y. \& Naqvi, M.H.A. (2019). The rise of social networking sites: An empirical investigation applying demographic differences and the technology acceptance model. Asia Pacific Journal of Marketing and Logistics, 32 (1):232252. https://doi.org/10.1108/APJML-01-2019-0029

Naqvi, M. H. A., Jiang, Y., Miao, M. \& Naqvi, M. H. (2020). The effect of social influence, trust, and entertainment value on social media use: Evidence from Pakistan. Cogent Business and Management, 7(1): 1723825. https://doi.org/10.1080/23311975.2020.1723825

Oum, S. \& Han, D. (2011). An empirical study of the determinants of the intention to participate in user-created contents (UCC) services. Expert Systems with Applications, 38(12): 15110-15121. https://doi.org/10.1016/j.eswa.2011.05.098

Phua, J., Jin, S. V. \& Kim, J. J. (2017). Uses and gratifications of social networking sites for bridging and bonding social capital: A comparison of Facebook, Twitter, Instagram, and Snapchat. Computers in Human Behavior, 72, 115-122. https://doi.org/10.1016/j.chb.2017.02.041

Rauch, S. M., Strobel, C., Bella, M., Odachowski, Z., \& Bloom, C. (2014). Face to face versus Facebook: Does exposure to social networking web sites augment or attenuate physiological arousal among the socially anxious? Cyberpsychology, Behavior and Social Networking, 17(3): 187-190. https://doi.org/10.1089/cyber.2012.0498

Rauniar, R., Rawski, G., Yang, J. \& Johnson, B. (2014). Technology acceptance model (TAM) and social media usage: an empirical study on Facebook. Journal of Enterprise Information Management, 27(1): 6-30. https://doi.org/10.1089/cyber.2012.0498

Sampasa-Kanyinga, H. \& Lewis, R. F. (2015). Frequent use of social networking sites is associated with poor psychological functioning among children and adolescents. Cyberpsychology, Behavior and Social Networking, 18(7): 380-385. https://doi.org/10.1089/cyber.2015.0055

Shchebetenko, S. (2019). Do personality characteristics explain the associations between self-esteem and online social networking behaviour? Computers in Human Behavior, 91, 17-23. https://doi.org/10.1016/j.chb.2018.09.017

Shi, J., Lai, K. K., Hu, P. \& Chen, G. (2018). Factors dominating individual information disseminating behavior on social networking sites. Information Technology and Management, 19(2): 121-139. https://doi.org/10.1007/s10799-017-0278-8

Skues, J. L., Williams, B. \& Wise, L. (2012). The effects of personality traits, self-esteem, loneliness, and narcissism on Facebook use among university students. Computers in Human Behavior, 28(6): $2414-2419$. https://doi.org/10.1016/j.chb.2012.07.012

Sombutpibool, P. (2011). The adoption of social networks in Thailand. Journal of Information Technology Impact, 11(1): 1-34.

Sponcil, M. \& Gitimu, P. (2013). Use of social media by college students: Relationship to communication and selfconcept. Journal of Technology Research, 4, 1-13.

Strayhorn, T. L. (2012). Exploring the impact of Facebook and Myspace use on first-year students' sense of belonging and persistence decisions. Journal of College Student Development, 53(6): 783-796. 


\section{Jiang et al.}

Suki, N. M., Ramayah, T. \& Ly, K. K. (2012). Empirical investigation on factors influencing the behavioral intention to use Facebook. Universal Access in the Information Society, 11(2): 223-231. https://doi.org/10.1007/s10209-011-0248-6

Sun, T. \& Wu, G. (2012). Traits, predictors, and consequences of Facebook self-presentation. Social Science Computer Review, 30(4): 419-433. https://doi.org/10.1177/0894439311425978

Tan, X., Qin, L., Kim, Y. \& Hsu, J. (2012). Impact of privacy concern in social networking web sites. Internet Research, 22(2): 211-233. https://doi.org/10.1108/10662241211214575

Voorveld, H. A. (2019). Brand communication in social media: A research agenda. Journal of Advertising, 48(1): 14-26. https://doi.org/10.1080/00913367.2019.1588808

Whiting, A. \& Williams, D. (2013). Why people use social media: A uses and gratifications approach. Qualitative Market Research: An International Journal, 16(4): 362-369. https://doi.org/10.1108/QMR-06-2013-0041

Wise, K., Alhabash, S. \& Park, H. (2010). Emotional responses during social information seeking on Facebook. Cyberpsychology, Behavior and Social Networking, 13(5): 555-562. https://doi.org/10.1089/cyber.2009.0365

Wilson, R. E., Gosling, S. D. \& Graham, L. T. (2012). A review of Facebook research in the social sciences. Perspectives on Psychological Science, 7(3): 203-220. https://doi.org/10.1177/1745691612442904

Wilcox, K. \& Stephen, A. T. (2012). Are close friends the enemy? Online social networks, self-esteem, and selfcontrol. Journal of Consumer Research, 40(1): 90-103. https://doi.org/10.1086/668794

Wilson, K., Fornasier, S. \& White, K. M. (2010). Psychological predictors of young adults' use of social networking sites. Cyberpsychology, Behavior and Social Networking, 13(2): 173-177. https://doi.org/10.1089/cyber.2009.0094

Yushi, J., Naqvi, M. H. A. \& Naqvi, M. H. (2018). Using social influence processes and psychological factors to measure pervasive adoption of social networking sites: Evidence from Pakistan. Emerging Markets Finance and Trade, 54(15): 34853499. https://doi.org/10.1080/1540496X.2017.1417834

Zhang, S., Kwok, R. C. W., Lowry, P. B., Liu, Z. \& Wu, J. (2019). The influence of role stress on self-disclosure on social networking sites: A conservation of resources perspective. Information and Management, 56(7): 103147. https://doi.org/10.1016/j.im.2019.02.002

Zhang, Y., Tang, L. S. T. \& Leung, L. (2011). Gratifications, collective self-esteem, online emotional openness, and traitlike communication apprehension as predictors of Facebook uses. Cyberpsychology, Behavior and Social Networking, 14(12): 733-739. https://doi.org/10.1089/cyber.2010.0042

Zhou, T. (2011). Understanding online community user participation: A social influence perspective. Internet Research, 21(1): 67-81. https://doi.org/10.1108/10662241111104884

\section{ACKNOWLEDGEMENT}

We gratefully acknowledge the support provided by National Natural Science Foundation of China (No.

71572156), Sichuan Wine Development Research Center (CJZB18-02), Sichuan Circular Economy

Research Center (XHJJ-1815), the Humanity and Social Science Youth Foundation of Ministry of

Education China (19YJC860033), and Southwest Jiao Tong University "One Belt and Road" research task project (268YDYLZ01). 


\begin{tabular}{|c|c|}
\hline Study author and year & Study Focus \\
\hline Kim et al., 2010; Chang, 2015 & Self-construal, social interdependent \\
\hline $\begin{array}{l}\text { Moore, K., \& McElroy, J. C. 2012; Marshall et al., } \\
\text { 2015; Amichai-Hamburger and Vinitzky, 2010; } \\
\text { Gosling et al., 2011; Eftekhar } \text { et al., 2014; Lee, E., } \\
\text { Ahn, J., \& Kim, Y. J. 2014; Lee et al., 2012; } \\
\text { Carpenter, 2012; Davenport et al., 2014; } \\
\text { Mehdizadeh 2010; Bergman et al. 2011; Fox and } \\
\text { Rooney, } 2015\end{array}$ & Big five personality traits \\
\hline Skues et al., 2012 & Personality traits \\
\hline Wilson et al., 2010 & Self-esteem \\
\hline Hughes et al., 2012 & Motivations \\
\hline Ellison et al., 2014 & Social capital \\
\hline Jin, 2013 & Social enhancement and social compensation \\
\hline Al-Debei et al., 2013 & Socializing, content sharing, and dating \\
\hline Whiting and Williams, 2013 & U\&G attributes \\
\hline Nadkarni and Hofmann (2012) & Impression management and social acceptance \\
\hline Wilcox and Stephen, 2012 & Shyness \\
\hline Wilson et al., 2010; Fox and Warber, 2013 & Social connection \\
\hline Hew, 2011 & Self -promotion \\
\hline Chang et al., 2015 & Social connection \\
\hline Kwak et al., 2014 & Impression management \\
\hline Junco, 2015 & Educational use \\
\hline Krishnan and Atkin, 2014; Lee and Chan, 2015 & Leisure activity \\
\hline Kim, Sohn and Choi, 2011 & Cultural aspect \\
\hline Strayhorn, 2012 & Demographics \\
\hline Ernst et al., 2013 & Hedonic factor: Enjoyments \\
\hline Hsu, Chang and Chen, 2012 & Hedonic factor: playfulness \\
\hline Hsu et al (2011); Reinecke et al., 2014 & Pleasure and arousal \\
\hline Rauch et al., 2014 & Emotional response \\
\hline Lin and Lu, 2011 & Telepresence \\
\hline Grieve et al., 2013 & Belonging \\
\hline Marwick and Boyd, 2014 & Privacy \\
\hline Sombutpibool, 2011 & Flow \\
\hline Lee, Noh and Koo, 2013 & Psychological factors \\
\hline Zhou, 2011 & Social identity \\
\hline Cheung et al., 2011 & Social identity, social norm, and we intention \\
\hline Leng et al., 2011 & Social norm \\
\hline Oum and Han, 2011 & Social trust \\
\hline Flynn and Black, 2011; Ma and Chan, 2014 & $\begin{array}{l}\text { Perceived encouragement to use and perceived ease } \\
\text { of use }\end{array}$ \\
\hline Zhang et al. 2011 & Collective self-esteem \\
\hline
\end{tabular}

Table 3. Literature Review Sources 